\title{
LINGÜÍSTICA TEXTUAL E TRADUÇÃO: REDEFININDO O CONCEITO DE "MARCA CULTURAL"
}

\begin{abstract}
João Azenha Junior*
RESUMO: Desde os trabalhos de Nida e Taber (1964, 1969) sobre a influência das culturas de chegada em textos a serem traduzidos, considerações teóricas sobre a presença de "marcas culturais" e, por conseguinte, sobre procedimentos analíticos voltados à identificação de tais marcas têm sido mais sistematicamente estudadas como resultado da chamada "virada cultural” dos Estudos da Tradução (Reiss, 1971, 1983; Nord, 1988, 1993; Snell-Hornby, 1986) e severamente criticadas pela abordagem desconstrutivista da tradução (por exemplo, Arrojo, 1986, 1992). Por sua vez, o desenvolvimento da Lingüística Textual também colaborou para o alargamento do conceito, trazendo-o, por assim dizer, do mundo exterior - onde ele parecia estar enraizado nos anos de 1960 - para o interior do texto e do discurso. Este trabalho tem por objetivo revisar brevemente essa virada conceitual e discutir suas conseqüências para o ensino de tradução. Exemplos tomados de textos traduzidos do alemão por estudantes brasileiros demonstram como o uso sistemático de conceitos da Lingüística Textual pode ser eficiente para ajudar os estudantes a identificarem camadas de sentido que, distantes da idéia de "marcas culturais" como referência a uma realidade concreta, definem um ponto de vista no texto de partida, legitimam interpretações que demandam ajustes no texto de chegada e podem, assim, ser consideradas culturais num sentido mais amplo do termo.
\end{abstract}

UNITERMOS: Lingüística Textual; marcas culturais; ensino de tradução.

* Universidade de São Paulo. O autor agradece à Profa. Dra. Masa Nomura pela revisão dos conceitos de Lingüística Textual empregados neste trabalho. 
ABSTRACT: Since the works of Nida and Taber $(1964,1969)$ on the influence of target cultures on texts to be translated, theoretical considerations on the presence of 'cultural marks' and consequently on analytical procedures that would serve to identify these marks have been more systematically studied as a result of the so-called 'cultural turn' in Translation Studies (Reiss, 1971, 1983; Nord, 1988, 1993; Snell-Hornby, 1986) and heavily criticized by the Deconstruction approach to translation (for instance, Arrojo, 1986, 1992). The development of Text Linguistics has also contributed to enlarge the boundaries of the concept, bringing it, so to speak, from the outside world - where it seemed to be embedded in the 60s - to the inner domain of the text itself and discourse. This paper aims at briefly revising this conceptual turn and at discussing its consequences for translation teaching. Examples taken from German texts translated by Brazilian students shall demonstrate how efficient the systematic use of text linguistics concepts can be to help students in identifying layers of meaning which, distant from the idea of 'cultural marks' as a reference to a concrete reality, define a point of view in the source text, legitimate interpretations that demand shifts in the target text and therefore can also be taken as cultural in a broader sense.

KEYWORDS: Text Linguistics; cultural marcs; translation teaching.

A noção de referente, de vínculo de um item lexical com a realidade exterior ao texto, é herança enraizada no senso comum e, portanto, trazida na bagagem, por assim dizer, pelos estudantes de tradução. Tal noção, centrada na oposição "mundo lingüístico $v s$ mundo real", sustenta uma noção de texto como espelho de um referencial extralingüístico e fruto da ação nãointerferente de um sujeito.

Desde os trabalhos de Nida e Taber (anos de 1960) ${ }^{1}$ e os Estudos da Tradução de base estruturalista, ${ }^{2}$ dois conceitos encontram eco até hoje entre os estudantes de tradução brasilei-

\footnotetext{
1 Cf. Nida (1964) e Nida \& Taber (1969).

2 Cf., entre outros, Mounin (1963) e Catford (1980).
}

TradTerm, 12, 2006, p. 13-32 
ros: de um lado, uma cisão entre o mundo lingüístico e o extralingüístico; de outro, uma noção de cultura sediada fora do texto, quer dizer, pertencente exclusivamente ao mundo exterior à linguagem. Como decorrência disso, a noção de uma "marca cultural" presente nos textos estaria associada a questões ligadas a características específicas dos universos culturais envolvidos e passariam a constituir um problema de tradução no momento em que, sendo próprias da cultura na qual foi gerado o texto de partida, não pudessem ser identificadas nem entendidas pela cultura à qual o texto traduzido se dirige.

A bem da verdade, a noção de cultura enquanto universo à parte, desconectado do universo lingüístico, animou a discussão sobre traduzibilidade e intraduzibilidade do início do séc. $\mathrm{XIX}^{3}$ até a década de 1970, aproximadamente. Wilss (1982), por exemplo, comenta:

A intraduzibilidade cultural ocorre quando fatores socioculturais cobrem um espectro diferente da experiência na SL [lingua-fonte] e na TL [lingua-alvo] e precisam ser levados a coincidirem em vista do sentido pretendido em cada instância (Wilss, 1982: 50). ${ }^{4}$

A citação de Wilss, além de reforçar a idéia da separação entre linguagem e realidade, considera a experiência um fenômeno mensurável objetivamente e sustenta a noção de que possa haver um "sentido pretendido" pelo autor e pelo tradutor, passivel - também ele - de ser aferido objetivamente. Essa posição de Wilss, que comenta questões de tradução de uma perspectiva exterior ao objeto de seu comentário, começa a ser mais sistematicamente contestada por volta de fins da década de 1970.

Por essa época, a crítica dos Estudos da Tradução de influência desconstrutivista ao modelo estrutural, centrado no

3 Refiro-me aqui, em especial, às reflexões de Wilhelm von Humboldt e Friedrich Schleiermacher, só para citar dois filósofos da linguagem alemães dessa época que se ocuparam de questões atinentes à tradução.

4 "Cultural untranslatability occurs when sociocultural factors cover a different range of experience in the SL [source language] and the TL [target language] and must be made to coincide in regard to the intended meaning in each instance". 
logos, questiona a divisão sujeito-objeto nas relações operadas através da linguagem e no interior dela, e - em decorrência disso - defende a inserção definitiva de um sujeito interferente e de seu ponto de vista na constituição do sentido em linguagem. $\mathrm{E}$ os trabalhos de Nida e Taber, bem como os de autores de base estruturalista, passam à mira de estudos que criticam a noção de um sentido transportável de texto para texto, de cultura para cultura, ainda que em formas (lingüisticas) diferentes. ${ }^{5}$

Também em meados da década de 1970, a chamada "virada cultural" nos Estudos da Tradução abre espaço para o diálogo interdisciplinar, ${ }^{6}$ alarga o conceito de cultura para todas as manifestações do espírito humano, defende a relação entre o mundo lingüístico e o extralingüístico como um continuum, redireciona a função da tradução para o receptor e - estando o sujeito-tradutor no centro da tomada de decisões - ressalta o recurso a estereótipos na determinação das estratégias funcionais de tradução. ${ }^{7}$

Acompanhando essa evolução, a inserção do sujeito e sua relação indissociável com um objeto - seja ele o mundo da experiência, seja o texto e o discurso - também estão presentes em estudos recentes da Lingüística Textual:

(...) percebemos os objetos tal como previamente definidos por nossas práticas culturais: a "realidade" é fabricada por toda uma rede de estereótipos culturais, que condicionam a própria percepção e que, por sua vez, são garantidos e reforçados pela linguagem, de modo que o processo de conhecimento é regulado por uma interação contínua entre práxis, percepção e linguagem. (Koch, 2004: 51, grifo da autora).

Desse modo, não que o referente - a "coisa" extralingüistica, como a denomina Koch (2004) - deixe de existir enquanto tal e também enquanto um problema de tradução, associado, por

\footnotetext{
5 Cf., por exemplo, Arrojo (1986, 1992).

6 Cf. entre outros, Snell-Hornby (1986) e sua reflexão sobre uma "visão holística" do processo de tradução, articulada com áreas do saber as mais diversas.

7 Cf. Reiss (1971, 1983), Nord (1988, 1993).
} 
exemplo, à noção de Realia. ${ }^{8}$ Características específicas das culturas continuam e continuarão sempre a constituir problemas de entendimento, seja no domínio do texto e do discurso, seja fora dele. $\mathrm{E}$ isso a despeito dos avanços disponibilizados pela pesquisa em ambiente eletrônico, que não estavam - e nem podiam estar - contemplados nas reflexões de Nida e Taber dos anos de 1960. Contudo, tal como considerado hoje, o referente deve sua existência a "um processo (não verbal) de cognição, de construção e de ordenação do universo" (Koch, 2004: 52; grifo meu), operado no interior do discurso.

Como decorrência disso, a construção do sentido em tradução - mesmo para aquelas passagens em que se verificam diferenças significativas no modo como duas culturas enxergam um fenômeno - desloca-se da noção do referente para a atividade da referenciação, entendida esta não como a relação entre o que está "dentro" e o que está "fora" do texto, mas como uma gama de recursos de que faz uso o produtor do texto, por um lado, e o leitor do texto, por outro, para construir, desconstruir e reconstruir cadeias significativas. Esse entrelaçamento de fios condutores de sentido somente ganha corpo na interação e parece constituir atualmente um centro de interesse da Lingüística Textual. Koch (2004) resume:

Pois bem: se o referente é fabricado pela prática social, o que dizer da atividade sociocognitivo-discursiva de referenciação? É essa uma das principais reflexões que vêm sendo empreendidas hoje no interior da Lingüistica Textual (Koch, 2004: 53).

Neste trabalho, restrinjo ao domínio do léxico minhas considerações sobre a contribuição da Lingüística Textual para o trabalho na aula de tradução. ${ }^{9}$ Por meio de exemplos extraídos do trabalho com tradutores iniciantes na Universidade de São Paulo, procuro demonstrar que itens lexicais, desde que consi-

8 Sobre a noção de Realia e de suas conseqüências para a tradução, cf. Markstein, 1999.

9 Para uma visão mais abrangente das contribuições da Lingüística Textual para a tradução, cuja discussão extrapolaria os limites deste trabalho, cf., por exemplo, Kapp (1974), Bell (1991) e Fawcett (1997). 
derados na sua inter-relação no interior do discurso, estabelecem campos semânticos que ajudam os estudantes a identificarem pontos de vista no texto de partida, legitimam interpretações que demandam ajustes no texto de chegada e, como conseqüência disso, também podem ser tomados como marcas culturais num sentido mais amplo do termo.

\section{No interior do texto e do discurso}

Desde o trabalho Cohesion in English (1976), de Halliday e Hasan, as relações de sentido tecidas no interior dos textos têm sido cada vez mais investigadas de forma integrada com outras abordagens dos estudos da linguagem - por exemplo, as perspectivas funcional e cognitiva -, no interior dos quais, e seguindo trajetória semelhante, estão também os Estudos da Tradução.

Até por volta de meados dos anos de 1980, percebe-se uma tentativa de se definirem em separado dois dos sete critérios de textualidade descritos por De Beaugrande e Dressler em 1981 a coesão e a coerência - como fenômenos associados, no primeiro caso, ao encadeamento linear dos componentes da superficie textual, e, no segundo, às dependências de natureza conceitual. Olhando em retrospectiva, uma tal concepção parece reforçar a idéia de que os sentidos possam se organizar e sobreviver no interior do texto, independentemente da ação do sujeito leitor (e também do tradutor), desde que respeitadas as normas dos sistemas lingüísticos envolvidos. É como se a escolha lexical e a disposição dos elementos na superfície do texto, desde que conectadas segundo normas previstas pela gramática, pudessem garantir a permanência e a eficácia de um sentido supostamente pretendido pelo autor do texto e imune às ações do tempo e de seus leitores.

Embora ainda amplamente aceita e compartilhada por estudantes em fase inicial do aprendizado de uma lingua estrangeira e também da tradução, uma tal concepção não mais resiste a uma investigação mais rigorosa. Baker (1992), por exemplo, referindo-se às definições de coesão e coerência, comenta: 
No caso da coesão, segmentos de linguagem são conectados entre si por força de dependências lexicais e gramaticais. No caso da coerência, eles são conectados por força de dependências conceituais ou de sentido, tal como percebidos pelos usuários da linguagem (Baker, 1992: 218; grifos meus). ${ }^{10}$

E também Fawcett (1997) afirma:

A 'coerência' é irmã gêmea da 'coesão', mas é um conceito um pouco mais dificil de se definir. Ele envolve não apenas aspectos tais como a lógica conceitual de como o texto é estruturado, o que com freqüência está refletido nos recursos coesivos, mas também o conhecimento de coisas tais como o assunto [tratado] e o modo como o mundo funciona. (Fawcett, 1997: 98; grifos do autor). ${ }^{11}$

A coerência deixa, assim, de ser algo próprio do texto-emsi para somente se constituir na interação com o usuário da lingua, quer dizer, o leitor ou o tradutor do texto. Nesse processo, o texto passa de mero depositário de sentidos previamente definidos a ponto de partida para uma rede de associações e dependências efetivadas no ato da leitura e que definem sua singularidade. Suprimida a distância entre um objeto (o textoem-si) e um sujeito (seu leitor e tradutor), as relações de sentido se constroem a cada interação e diferentemente. Essa noção de interação calcada na experiência é responsável pelos shiftings interpretativos de um mesmo fenômeno e está na base da reflexão aqui pretendida por um alargamento do conceito de "marca cultural".

Tudo isso que aos estudiosos da linguagem pode parecer óbvio, não o é para os estudantes de tradução. E mesmo o con-

\footnotetext{
10 "In the case of cohesion, stretches of language are connected to each other by virtue of lexical and grammatical dependencies. In the case of coherence, they are connected by virtue of conceptual or meaning dependencies as perceived by language users."

11 "'Coherence' is the twin of 'cohesion', but it is a rather more difficult concept to define. It involves not only such matters as the conceptual logic of how a text is structured, which will often be reflected in cohesive devices, but also knowledge of such things as subject matter and how the world works."
} 
tato com tais reflexões, no nível da teoria, não significa que o conceito será por eles interiorizado e posto em prática, seja na fase preparatória para a tradução, seja posteriormente, na avaliação crítica do trabalho. Comentários tais como "mas isso está no dicionário", ou então "mas eu encontrei tal correspondente na Internet", ou mesmo "acho que nesta passagem o autor quis dizer que...", entre tantas outras, confirmam a cisão sujeito-objeto e sublinham uma visão fragmentada de linguagem, em que a palavra isolada, sem relação com seu entorno, continua a ocupar o centro das atenções. Salvo exceções, o estudante de tradução insiste em trabalhar o texto linearmente, certo de que chegará ao sentido supostamente pretendido pelo autor se se ativer, na superficie, à distribuição dos elementos na sentença e, no domínio da sintaxe, se respeitar as normas do sistema para o qual traduz.

Sob orientação, contudo, é possivel que o tradutor iniciante perceba que a relação dos itens lexicais entre si organiza e reorganiza cadeias significativas a cada etapa da leitura e pode estabelecer campos semânticos capazes de ativar molduras, padrões e esquemas cognitivos, que ora dão sustentação à continuidade do tema abordado, ora provocam rupturas que apontam para desdobramentos temáticos. Nesse contexto, a "marca cultural" do texto a ser traduzido - entendida esta mais no sentido do modo como cada um lê e interpreta o mundo - desloca-se da relação entre um item lexical e seu correspondente no universo extralingüístico para o interior da tessitura do discurso. Esse deslocamento suscita questões cruciais para o tradutor, conforme nos lembra Bell (1991):

(...) a tentativa de conseguir que o texto 'faça sentido' (...) levanta uma série de questões, que são de importância considerável para o tradutor: (1) qual mundo estamos tentando fazer coincidir com o texto, considerada a subjetividade da experiência pessoal e a certeza de que culturas diferentes percebem (ou, pelo menos, moldam) o mundo diferentemente?, (b) como podemos agir sobre a realização da natureza altamente interativa do texto? e (c) como podemos chegar a uma compreensão basilar do processamento de um texto, a menos que encontremos caminhos para relacionar o 'mundo real' com o 'mundo textual' de 
modo a que isso 'faça sentido' para nós? (Bell, 1991: 166167; grifos do autor). ${ }^{12}$

\section{O que faz Stalin nos funerais de João Paulo II?}

Praça de São Pedro, Roma, 9 de abril de 2005. Sob uma cobertura dos meios de comunicação jamais vista, o mundo assiste aos funerais do papa João Paulo II. O texto da edição online da revista Der Spiegel, ${ }^{13}$ do correspondente Dominik Baur, descreve e comenta a cerimônia. Em São Paulo, um grupo de estudantes lê e discute, quase em tempo real, o texto de Baur. Eles preparam o texto para ser traduzido. As condições para a compreensão são favoráveis; afinal, mesmo em fase de aquisição do alemão como língua estrangeira, a base de conhecimento compartilhado é ampla: todos acompanharam a agonia e a morte do pontífice mais popular da história da Igreja Católica.

O trabalho em sala de aula começa com a determinação do lugar de que fala o repórter. O texto de Baur pretende estar, como ele, ancorado em Roma. Essa ancoragem ganha corpo numa profusão de itens lexicais que reconstroem, no texto, a capital italiana e são conectados seja por co-referência - quer dizer, pelo emprego de dêiticos textuais, pró-formas etc. -, seja por substituição e elipse. Em suma, por mecanismos de reiteração e remissão: ${ }^{14}$

\footnotetext{
12 “(...) the attempt to get the text to 'make sense' (...) raises a number of questions which are of considerable significance for the translator: (a) which world are we attempting to match with the text, given the subjectivity of personal experience, the certainty that different cultures perceive (or, at least, model) the world differently?, (b) how can we act upon the realization of the highly interactive nature of text? and (c) how can we come to any principled understanding of text-processing, unless we find ways of relating 'real world' and 'text world' together in a way which 'makes sense' for us?" 13 O texto usado para a seleção dos exemplos intitula-se "Ruhe nach der Invasion der Pilger" ("Paz depois da invasão dos peregrinos") e foi publicado na versão online da revista Der Spiegel em 10 de abril de 2004. O texto foi trabalhado em sala de aula com alunos ainda em fase de aquisição de alemão como língua estrangeira na Universidade de São Paulo, Brasil.

14 Nos exemplos arrolados neste trabalho, o número entre parênteses refere-se à linha do texto em alemão (cf. Anexo) de que foi extraído o exemplo.
} 
(1) Aus Rom berichtet ...

[de Roma relata...]

(2) Eine Stadt atmet auf ...

[Uma cidade respira aliviada...]

(3) Millionen Menschen (drangen) ... in die italienische Hauptstadt.

[Milhões de pessoas afluíram para a capital italiana...]

(4) Selbst im Vatikan herrscht touristischer Alltag ...

[Mesmo no Vaticano o movimento de turistas voltou ao normal...]

(19-20) ... Pilger, die ... in die Ewige Stadt gekommen waren, ... [Peregrinos, que haviam chegado à Cidade Eterna...]

(21) Am Ufer des Tibers, gegenüber von der Engelsburg ... [À margem do Tibre, defronte ao Castelo de Sant'Angelo...]

(25-26) Am Petersplatz hat sich die Lage ... normalisiert ... [Na Praça de São Pedro,... a situação se normalizou...]

(28-29) Am Obelisken in der Mitte des [Peters] Platzes ... [Junto ao obelisco, no centro da Praça (de São Pedro)...]

(35-36) ... die zum Petersplatz führende Via Conziliazione ... [a Via Conziliazione, que leva à Praça de São Pedro...]

(40) $\quad .$. die Schlange derer, die in den Dom wollen, ... [as filas daqueles que querem entrar na Basilica...]

(44-45) Erst am Montag öffnet der Vatikan seine Krypta wieder ...

[Somente na segunda-feira o Vaticano reabrirá sua cripta ...]

(49) Im Kirchenstaat haben ... die Novendiale begonnen ... [No Estado da Igreja começaram os Novendiale ...]

(50) Täglich wird im Petersdom eine Messe ... zelebriert...

[Diariamente é celebrada uma missa na Catedral de São Pedro]

(53) ...die Kirchenführer [begeben sich] dann in die Sixtinischen Kapelle ...

[Os dirigentes da Igreja encaminham-se, então, à Capela Sixtina]

O emprego desses recursos que situam o relato no espaço e no tempo e que visam a determinar o lugar (concreto) de que 
fala Baur é reforçado por alusões diretas ou indiretas a manifestações de instituições, autoridades e cidadãos comuns:

(37-39) 1,4 Millionen Menschen, heißt es heute im italienischen Innenministerium, seien in diesen Tagen an dem aufgebahrten Leichnam vorbeidefiliert ... [1,4 milhão de pessoas, segundo declarações de hoje do Ministério do Interior italiano, teriam desfilado nesses dias pelo esquife do papa...]

(55-56) „Grazie!” ... steht heute ... auf der Titelseite des „Osservatore Romano" ...

[„Grazie!” ... estampa hoje a manchete do Osservatore Romano...]

(58-61) Es sei als müsse man ein Jubiläumsjahr ... organisieren, hatte ... Bürgermeister Walter Veltroni geklagt, aber das in nur zwei Tagen.

[É como se se tivesse de organizar um jubileu... - queixou-se o prefeito Walter Veltroni -, só que em apenas dois dias].

(68-69) Staatspräsident Carlo Azeglio Ciampi dankte den Römern, ...

[O presidente Carlo Azeglio Ciampi agradeceu aos romanos...]

(70-71) Auch US-Präsident George Bush, der britische Premier Tony Blair und Spaniens König Juan Carlos stimmten in das Lob ein.

[Até mesmo o presidente dos Estados Unidos, George Bush, o chanceler inglês Tony Blair e o rei Juan Carlos da Espanha engrossaram o coro de elogios...]

(73-76) Ein Kellner einer Pizzeria ... beschwert sich: „Wir sind leer ausgegangen." Er habe gedacht, wenn die Pilger kommen, werde er einen viel größeren Umsatz machen. „Aber die haben ja alle nur Sandwichs gegessen.

[Um garçom de uma pizzeria... queixa-se: "Nós não faturamos nada". Ele havia pensado que, quando os peregrinos chegassem, o faturamento do estabelecimento seria muito maior. "Mas eles acabaram comendo só sanduíches."] 
Valendo-se do meio digital em que o texto é veiculado, a ancoragem do texto na cidade de Roma é reforçada, ainda, pela possibilidade de o usuário empreender uma "viagem virtual pelo Vaticano", bastando para isso clicar no ícone correspondente. Ademais, o aspecto da informatividade é complementado pela seção "Zum Thema" (Sobre este tema), em que se facilita, por meio de links, o acesso do leitor interessado a outras matérias da revista concernentes ao mesmo assunto.

A despeito do emprego de todos esses recursos, o curso da análise põe em dúvida o fato de ser Roma o lugar de que fala Baur. E o abandono da Cidade Eterna começa, para os estudantes brasileiros, no momento em que Stalin, pela voz de Baur, aparece na Praça de São Pedro e pergunta: - Quantas divisões têm o papa? (17). Para os aprendizes de tradução brasileiros, a alusão ao líder soviético causa estranheza: "O que faz Stalin nos funerais de João Paulo II?”, eles perguntam. Começa aqui um trabalho de reconstrução de relações que abrirá portas para a reconsideração do lugar de ancoragem do texto a ser traduzido e de seu grau de dificuldade.

A bem da verdade, a pergunta de Stalin e seus ecos nos estudantes brasileiros convidam a uma releitura do texto, desta vez com a atenção voltada para uma faixa do léxico que sugere uma camada de sentido sobreposta à primeira. Recobrindo o caráter pretensamente informativo, esta "demão" sugere um desdobramento, na esfera política, para os fatos descritos: estaria a alusão a Stalin associada ao fato de o pontífice ter cooperado para o desmonte do bloco socialista? E, nesse ponto, como ainda estamos no interior do conhecimento prévio armazenado sobre a história política da Europa, o texto é relido com a atenção voltada para indícios que possam ser relacionados, na memória dos estudantes-leitores, a esses mesmos conhecimentos. Com efeito, já a partir do título lemos:

(0) Ruhe nach der Invasion der Pilger

[Paz após a invasão dos peregrinos]

(14) Doch der Begeisterung der Massen Abbruch zu tun ... [Mas para estragar a empolgação das massas ...]

(36-37) ... Pilger aus aller Welt Schlange standen, um dem Pontifex die letzte Ehre zu erweisen. 
[Peregrinos do mundo inteiro ficaram em filas para renderem sua última homenagem ao pontífice.]

(37-38) 1,4 Millionen Menschen, ..., seien an dem ... Leichnam vorbeidefiliert ${ }^{15}$

[1,4 milhão de pessoas... teriam desfilado pelo esquife...]

(41-42) Und trotz der Sicherheitskontrolle, ...

[E apesar do controle de segurança,...]

(54) Solange sie (die Kardinäle) tagen, bleiben die Zugänge vermauert $^{16}$

[Enquanto (os cardeais) permanecerem reunidos, os acessos (à Capela Sixtina) permanecem interditados]

(66-67) Beim Abzug ${ }^{17}$ der Menschenmassen aus der Stadt, ... [À medida que as pessoas batem em retirada, deixando a cidade,...]

(73) Denn die wenigsten haben von dem Ansturm ${ }^{18}$ der Millionen profitiert.

[Pois só uma minoria lucrou com a investida dos milhões (de pessoas).]

(76-77) Restaurants konnten sich die zumeist jugendlichen Papstanhänger ${ }^{19}$ offenbar nicht leisten.

[Ao que tudo indica, os adeptos do papa, em sua maioria jovens, não puderam se dar ao luxo de comer em restaurantes.]

15 O Duden Universal Wörterbuch (1996: 324) registra para este verbo a acepção de um desfile solene, como o das paradas militares, e a de um desfile de tropas diante de autoridades.

16 O verbo "vermauern" (cf. Duden 1996: 1654), empregado aqui no sentido de interdição (dos acessos à Capela Sixtina), tem em sua raiz o substantivo "Mauer" [muro]. Ainda que não se possa afirmar ter sido esta a intenção do uso, sua relação nesse campo semântico com o muro que dividia os dois blocos não apenas é possivel para o estudante brasileiro, como também é justificada.

17 Para este termo, encontramos - na acepção militar do verbete (cf. Duden Duden 1996: 76) - a batida em retirada, (por exemplo, de tropas).

18 Derivado do verbo anstürmen, o substantivo Ansturm aparece associado, por exemplo, ao ataque do inimigo, o que autoriza sua inclusão no interior do campo lexical bélico (cf. Duden 1996: 125).

19 O substantivo Anhänger, nos usos descritos no dicionário (cf. Duden 1996: 112), é empregado para se descrever o adepto de uma linha filosófica ou ideológica, ou o militante de um partido. 
O exame das relações entre os itens lexicais citados, além de aguçar o senso dos estudantes para uma faixa do léxico que lhes era desconhecida e de vincular essa faixa a fatos históricos, confirma a suspeita sobre a existência de uma camada interpretativa de natureza político-ideológica. A partir dela se pode reconsiderar, inclusive, a menção a Bush, Blair e Juan Carlos, três dos mais de duzentos chefes de Estado presentes à cerimônia. Coincidência ou não, os três personagens políticos foram parceiros dos americanos na guerra contra o Iraque, fortemente criticada no interior do ambiente alemão.

À luz desse patamar de interpretação, ganham relevo também três referências à Polônia e aos poloneses, já que a Polônia não é apenas o país natal do papa falecido, mas também um país pertencente ao ex-bloco comunista. Tomemos, de início, a seguinte cena na Praça de São Pedro: termina a cerimônia, um funcionário da Prefeitura recolhe com uma pá um monte de lixo deixado pelos participantes da cerimônia (ou pelos peregrinos, como prefere Baur): são velas, flores e garrafas de água. Ao final do parágrafo, lemos:

(32-34) Eine polnische Touristin fischt sich noch schnell ein paar unbeschädigte rote Plastikrosen aus dem Haufen. [Rapidamente, uma turista polonesa ainda tem tempo de fisgar do lixo algumas flores de plástico vermelhas que não estavam estragadas.]

No interior do tecido discursivo que vem sendo tecido pelas considerações anteriores, os estudantes brasileiros julgam pertinente indagar: "Mas por que justamente uma turista polonesa? E por que rosas vermelhas, símbolos do socialismo? E por que as rosas são de plástico, quer dizer, são falsas? E, por fim, por que estão no lixo? Não seria esta uma imagem-síntese forte demais? Outra questão difícil de ser entendida pelo aluno brasileiro: não seria este um detalhe dispensável? O que isso acrescenta à descrição dos fatos? E, finalmente, não é depreciativo para os poloneses serem citados num texto jornalístico apanhando coisas do lixo? Bem, a alusão à Polônia é reforçada ainda por duas outras passagens: 
(21-23) Am Ufer des Tibers, gegenüber von der Engelsburg, steht noch ein letzter der polnischen Reisebusse, die die Pilger aus der Heimat des Papstes zum Vatikan gebracht hatten. [À margem do Tibre, defronte ao Castelo de Sant'Angelo, ainda está parado um último dos ônibus de turismo que trouxeram os peregrinos da terra natal do papa até ao Vaticano].

(76-78) Restaurants konnten sich die zumeist jugendlichen Papstanhänger offenbar nicht leisten - kein Wunder, denn selbst der monatliche Facharbeiterlohn eines Polen schmilzt in einem römischen Restaurant wie Eis in der Sonne.

[Ao que tudo indica, os adeptos do papa, em sua maioria jovens, não puderam se dar ao luxo de comer em restaurantes; não é de estranhar, pois até mesmo o salário mensal de um trabalhador especializado polonês derrete num restaurante romano como sorvete ao sol.]

Em si, a primeira passagem nada teria de depreciativa em relação aos poloneses. Contudo, na esteira das indagações anteriores, os estudantes de tradução perguntam: "Mas eram só ônibus de poloneses estacionados às margens do Tibre?" Já a segunda, ao final do texto, é bastante incisiva quanto ao poder aquisitivo dos poloneses e nos faz rever a interpretação da passagem anterior: "Provavelmente, então, os poloneses não têm dinheiro nem para viajar de trem ou de avião até Roma", comentam os estudantes. Aos olhos do estudante brasileiro, as três passagens apontam para uma visão crítica - e, por que não dizer, irônica - em relação ao ex-bloco comunista, além de uma visão pouco simpática em relação aos poloneses. E de quem seria essa visão? Do repórter? Da linha editorial da revista? Dos alemães? Independentemente do fato de isso se confirmar ou não na prática, o exame do texto a partir das relações de coesão lexical permite que se levantem tais questões. E elas apontam para uma opinião ancorada numa realidade cultural diversa da brasileira.

A questão da ironia, mencionada no parágrafo anterior, permite que se arrisquem interpretações para a visão do repórter acerca dos fatos que relata, desta vez quanto à cerimônia em 
si. Já no box da matéria, encontra-se o termo "Papaboys" e o acompanhamento das referências aos participantes, complementado pelas ilustrações que dão suporte à matéria, permite a associação do conjunto com a apresentação de um superastro da música pop:

(2) Die Präsidenten und Papaboys haben Rom verlassen. [Os presidentes e os papaboys deixaram Roma.] Die Millionen Fans ... jubelten ihrem toten Idol zu... [Milhões de fãs saudaram em júbilo seu ídolo morto...]

(Fig. 2) Die Folgen des Mega-Events wurden schnell beseitigt (legenda da foto).

[O que sobrou do megaevento foi rapidamente eliminado]

(46-47) ... keine Papaboys oder -girls, wie sich die jugendlichen Fans des Papstes nennen

[Nenhum papaboy ou papagirl, como se denominam os jovens fãs do papa,...]

(48) ... die (Fans), die ... den Vatikan zu einem Festival des Glaubens besucht hatten.

[(fãs), que tinham visitado o Vaticano para um festival de fé.]

O exame dessa faixa do léxico deixa entrever um certo descaso quanto à seriedade do evento, a solenidade dos funerais e o sentido verdadeiramente pungente da cerimônia. Tal interpretação, mais facilmente identificada pelos estudantes brasileiros, é reforçada pelo parágrafo de abertura do texto. Nele, Baur comenta a ação do vento sobre a batina dos cardeais - uma imagem caricatural reforçada pela ilustração que acompanha o texto (Fig. 3) - e sobre o "Livro dos Livros":

(10-13) Mit den Soutanen der Kardinäle trieb er [der Wind] Schabernack, das Buch der Bücher auf dem Sarg klappte er, nachdem er eine Weile durch die Seiten geblättert hatte, ganz zu. [Fez (o vento) troça com a batina dos cardeais e fechou completamente o Livro dos Livros, depois de folheá-lo por alguns instantes.] 
A rigor, e de acordo com as explicações veiculadas na televisão por especialistas no cerimonial do Vaticano, o vento (uma metáfora para a mão de Deus?) deveria escolher um trecho do Evangelho a presidir e inspirar a cerimônia dos funerais. Se o vento torna risivel a presença dos cardeais e, sem escolher um trecho do Evangelho, fecha o livro, o espírito verdadeiramente religioso da cerimônia fica comprometido, e o que se vê - e se lê - em seguida é a descrição da "ressaca" do show de um astro da música pop.

\section{Se for para traduzir, então traduzir o quê?}

A partir de uma base de um conhecimento prévio comum, nesse caso associado à morte do papa João Paulo II, o texto estudado resiste a uma análise e a um tratamento lineares e somente revela camadas de sentido sobrepostas à sua pretensa objetividade no momento em que é lido e discutido, bem como ao se considerarem campos semânticos estabelecidos a partir de um exame do léxico baseado na inter-relação. Nesse sentido, o que se poderia chamar aqui de marca cultural pode e deve ser aferido em relações que ativam esquemas cognitivos e permitem identificar diferentes ângulos, a partir dos quais o repórter observa o que descreve e comenta.

A discussão sobre tais aspectos permite indagar sobre a natureza mesma do texto jornalístico, discutir a noção de objetividade e de compromisso com a verdade, comumente atribuídas a esse tipo de texto, perceber algumas características do jornalismo opinativo e refletir sobre linhas editoriais. No domínio da tradução, esse exercício permite, ainda, indagar se os procedimentos tradutológicos para esse tipo de texto não deveriam levar em conta questões concernentes não apenas aos sistemas lingüísticos envolvidos, mas também - e sobretudo - às culturas e ao próprio sistema de imprensa vigente no país para o qual a tradução se destina. ${ }^{20}$

Além disso, aquilo que para o leitor do ambiente lingüístico alemão teria um sentido mais facilmente identificável - por

20 Cf. Zipser (2002). 
exemplo, a referência à história, à divisão da Europa em blocos de orientação político-ideológica distintas, o resgate de uma imagem que se fez (ou que se tem) dos poloneses e a associação do evento descrito a uma festa pop (o que também pode ser visto como uma crítica à própria Igreja Católica, num continente em que ela tem perdido adeptos), tudo isso parece distante do horizonte de expectativas do leitor brasileiro médio. São dimensões de sentido a que ele possivelmente não terá acesso sozinho e que, portanto, menos que informar, terão o efeito de constituir empecilhos à compreensão.

Por fim, o objetivo mesmo da matéria, aquilo que poderia ser considerado o fato que deu ensejo à sua redação - "A paz após a invasão dos peregrinos" - poderia ser contestado no momento da tradução. Afinal, toda a matéria se volta para a constatação, não sem um quê de admiração, de que apesar de toda a afluência de fiéis, apesar de todos os transtornos do trânsito na cidade de Roma, apesar do calor etc., tudo acabou bem. Ora, tudo isso só teria uma razão de se transformar em matéria de imprensa se houvesse a priori uma expectativa no sentido contrário. Quer dizer, se o que se esperasse fossem problemas de organização que resultassem em caos. Para os brasileiros, não há a priori a expectativa de que os italianos não sejam exatamente o exemplo de organização que um alemão, por exemplo, poderia esperar. "Será que os alemães achavam que os italianos não conseguiriam vencer as dificuldades de um evento de tamanhas proporções?”, perguntam os estudantes, já em dúvida sobre se o texto proposto teria mesmo algo a dizer aos brasileiros.

Assim, ao desfazer a primeira impressão de que um texto de divulgação veiculado online não conteria "marcas culturais", o exercício de preparação da tradução convida a uma redefinição desse conceito, a ser buscado não mais na chamada "realidade extralingüística", e sim no modo como cada cultura enxerga o mundo e o reconstrói no interior do discurso.

\section{Referências bibliográficas}

ARROJO, Rosemary. (1986) Oficina de tradução. A teoria na prática. São Paulo: Ática. 
. (1992) O signo desconstruido. Implicações para a tradução, a leitura e o ensino. Campinas (SP): Pontes.

BAKER, Mona. (1992) In other words. A coursebook on translation. London \& New York: Routledge.

BELL, Roger. (1991) Translation and translating. Theory and Practice. London \& New York: Longman.

CATFORD, J.C. (1980) Uma teoria lingüística da tradução. Campinas (SP): Cultrix/PUC.

De BEAUGRANDE, R.A. \& DRESSLER, W.U. (1981) Einführung in die Textlinguistik. Tübingen.

FAWCETT, Peter. (1997) - Translation and Language. Linguistic theories explained. Manchester: St. Jerome Publishing.

HALLIDAY, M.A.K. \& HASAN, R. (1993) Cohesion in English. London: Longmann (1a. ed. 1976).

HATIM, Basin \& MASON, Ian. (1997) The translator as communicator. London \& New York, Routledge.

KAPP, Volker. (1974) Übersetzer und Dolmetscher. Heidelberg: Quelle \& Meyer (UTB 325).

KOCH, Ingedore G. Villaça. (2003) Desvendando os segredos do texto ( $2^{\mathrm{a}}$. edição). São Paulo: Cortez.

. (2004) Introdução à Lingüística Textual. São Paulo: Martins Fontes.

MAINGUENEAU, Dominique. (1996) Elementos de lingüística para o texto literário. São Paulo: Martins Fontes.

MARSTEIN, Elisabeth. (1998) Realia. In: SNELL-HORNBY, Mary et alii (ed.) - Handbuch Translation. Tübingen: Stauffenburg.

MOUNIN, Georges. (1975) Problemas teóricos da tradução (Trad. Dominique Aury). São Paulo: Cultrix.

NIDA, Eugene. (1964) Toward a Science of Translating. Leiden: Brill. ; TABER, Charles R. (1969) The Theory and Practice of Translation. Leiden: Brill.

NORD, Christiane. (1988) Textanalyse und Übersetzen: theoretische Grundlagen, Methoden und didaktische Anwendung einer übersetzungsrelevanten Textanalyse. Tübingen: Narr.

. (1993) Einführung in das funktionale Übersetzen. Tübingen: Francke (UTB).

. (2003) Kommunikativ handeln auf Spanisch und Deutsch. Ein übersetzungsorientierter funktionaler Sprach- und Stilvergleich. Wilhelmsfeld: Gottfried Egert. 
REISS, Katharina. (1971) Möglichkeiten und Grenzen der Übersetzungskritik. München: Hueber.

. (1983) Texttyp und Übersetzungsmethode. Der operative Text $\left(2^{\mathrm{a}}\right.$. ed.). Heidelberg: Groos.

SNELL-HORNBY, Mary. (ed.) (1986) Übersetzungswissenschaft. Eine Neuorientierung. Tübingen: Francke Verlag (UTB für Wissenschaft: Uni-Taschenbücher; 1415).

WILSS, Wolfram. (1982) - The science of translation. Problems and Methods. Tübingen: Narr.

ZIPSER, Meta. (2002) - Do fato à reportagem: as diferenças de enfoque e a tradução como representação cultural. Tese de Doutorado. São Paulo, FFLCH-USP. 